NBER WORKING PAPER SERIES

HAS STATE REDISTRIBUTION POLICY

GROWN MORE CONSERVATIVE?

Robert Moffitt

Working Paper No. 2516

NATIONAL BUREAU OF ECONOMIC RESEARCH

1050 Massachusetts Avenue

Cambridge, MA 02138

February 1988

ne author would like to thank participants of seminars at the NBER and the University f Maryland for comments. Financial support was provided by a grant from the U.S. epartment of Health and Human Services to the Institute for Research on Poverty. 17 errors and and opinions are those fo the author and not the sponsoring agency. re research reported here is part of the NBER's research program in Taxation. Any oinions expressed are those of the author and not those of the National Bureau of conomic Research. Support from. The Lynde and Harry Bradley Foundation is grateful1y -knowledged. 
NBER Working Paper \#2516

February 1988

\title{
Has State Redistribution Policy \\ Grown More Conservative?
}

\begin{abstract}
It is well-known that real benefits in the major cash transfer program in the U.S.--the Aid to Families with Dependent children (AFDC) program--have fallen drastically over the past twenty years. State legislatures, which set AFDC benefit levels, have failed to increase nominal benefits to keep up with inflation, resulting in a 25 percent decline in real benefits between 1960 and 1984. The most popular explanation for this decline is that state legislatures, reflecting the changing preferences of voters, have grown more conservative in their tastes for redistribution. The evidence presented in this paper is consistent instead with a different explanation, that legislatures have let federally-financed food stamps displace state-financed AFDC benefits. A similar displacement of AFDC by Medicaid benefits appears to have occurred. Aside from implying that preferences for redistribution have not in fact changed, the results also show that the total transfer benefit has increased, as should be expected from growing income levels. The findings also imply that neither the Food Stamp progran nor, presumably, any other lump-sum transfer provided by Congress is likely to have any effect on the incomes of the poor female-head population. Instead, such programs will merely provide budget relief to the states.
\end{abstract}

Robert Moffitt

Department of Economics

Brown University

Providence, RI 02912

(401) $-863-2779$ 


\section{INTRODJCTION}

The decline in real AFDC benefits over the 1970 s and 1980 s is one of the most widely-noted trends in the U.S. welfare system in recent years. It has been used as part of the explanation for the reversal in the historic decline in poverty rates, for poverty rates started rising around 1980 . It is often cited in the popular press as evidence for a growing conservative climate, and it is currently playing a role in welfare reform discussions in washington over arguments for a federally-mandated minimum state AFDC benefit. It has also been used as an argument against the thesis that AFDC destabilizes marital unions, for the rise in the divorce rate and the rate of femaleheadedness in the U.S. has occurred over the same period that AFDC benefits have fallen.

The alternate explanation explored in this paper is that the decline reflects a substitution of federally-funded Food stamp benefits for partially state-funded AFDC benefits. State legislatures, which set the level of AFDC benefits, must pay approximately 40 percent of the marginal costs of benefit increases after federal matching. On the other hand, Food stamp benefits are set by the U.S. Congress and are an externally provided extra benefit from the point of view of state legislatures. If it is the total transfer to its poor that enters the state utility function for the utility function of the median voter), Food Stamp benefits will displace AFDC dollars on a one-for-one basis. The decline in real AFDC benefits thus could be a result of the increase in Food 5 tamp benefits that occurred over the 1970 s and 1980 . 
This hypothesis has been examined previously by Hulten et al. (1982), Gramlich (1982), Orr (1979), and Plotrick and winters (1985). Orr found that Food stamps substituted for AFDC benefits on a one-for-one basis while Gramlich and Plotnick-Winters found there to be no substitution. Hulten et a1. found evidence of substitution but stressed the extreme non-robustness of the models that have been used. The variance in results in these studies may be, in part, a reflection of a key difficulty in testing the hypothesis. The Food stamp berefit schedule is uniform in the nation as a whole, hence a cross-section regression of state-specific AFDC benefits on a standardized Food stamp benefit is not possible. Moreover, the number of time periods available over the 1970 s and 1980 s is too small to conduct a reliable timeseries analysis, and the evidence is strong that the states were not in equilibrium in those years anyway. The previous studies attempted to circumvent this problem by using various sources of cross-sectional variation in the Food stamp benefit actually paid out in a state to achieve identification of the Food stamp substitution effect. However, the validity of using such variation to measure the substitution effect is subject to question and, in any case, the amount of such variation is small.

In this paper a more direct method of attack is taken. Cross-sectional regressions of AFDC benefits are estimated at a point in time (1960) prior to the introduction of Food stamps, and the results are then used to forecast the sum of AFDC and Food stamps at a later time (viz., in 1984). If the substitution hypothesis is correct, the 1960 regression should correctly forecast the later sum. This method, while direct, is also fairly heroic. Time-series forecasts from cross-sectional regressions are notorious ly poor 
and, in this case, there is an additional difficulty created by the transformation of the U.S. welfare system between 1960 and 1984 , making it perhaps unlikely that there has been no structural change in the AFDC benefit equation. But the possibly quixotic nature of the exercise also makes it a much stronger test of the hypothesis than has been previously attempted. The results indicate surprisingly strong support for the substitution hypothesis. Forecasts of the AFDC-Food Stamp sum to 1984 are only about $\$ 60$ per month higher than the actual sum, relative to a drop in the real AFDC benefit of $\$ 120$ per month since $1960(1982$ dollars $)$. When the Medicaid program is introduced, a stronger set of results is obtained. The AFDC benefit in 1960 was $\$ 200$ per month lower than the sum of AFDC, Food Stamps, and Medicaid in 1984; but a backcast of the 1960 AFDC benefit from a 1984 regression with the benefit sun as the dependent variable comes within $\$ 9$ of the 1960 AEDC benefit. Finally, almost all tests conducted on 1960 and 1984 differences find that the null of no structural change cannot be rejected.

In the next section of the paper, the background time-series trends in the $A F D C$ benefit, and in variables that night have caused its decline, are discussed. The models and econometric methods used to test the Food stamp hypothesis are discussed in section III, followed by a presentation of the main results in section. IV. A supplementary analysis of the AFDCU program (that for which males are eligible) is reported in section V. A sumary and a discussion of the policy implications of the paper are provided in the last section. 


\section{TIME-SERIES AND INSTITUTIONAL BACKGROUND}

A relative brief graphical exposition of the relevant trends should provide a proper context for the econometric work. The dramatic reduction in real AFDC benefits since the late $1960 \mathrm{~s}$ is illustrated in Figure 1. As the figure indicates, the real benefit grew steadily into the early 1960 s and accelerated slightly in the mid-1960s. But around 1967 or 1968 , the benefit increase came to a halt and benefizs took a sharp nosedive, setting off a fall which continued all the way to 1981 . Since 1981 the benefit has leveled off and has remained essentially constant.

That changes in the U.S. political climate leading to more conservative policies occurred at about the same time as the benefit decline leads to the obvious hypothesis that the benefit reduction has resulted from changes in preferences toward redistribution. State legislatures, which set AFDC benefits, are traditionally more conservative than the Congress in any case and could be argued to be particularly susceptible to changes in the attitudes of voters. Nevertheless, there could be economic causes of the change as well, and these clearly need to be explored.

One such alternative hypothesis is suggested by the trend in the AFDC caseload, also shown in Figure 1. The increase in the benefit in the early 1960 s was followed shortly thereafter by an explosion in the AFDC caseload, for the number of AEDC families per capita almost tripled over the six years between 1966 and 1972. Although the caseload has since leveled off, the subsequent reduction in the benefit may simply have been a response to the 


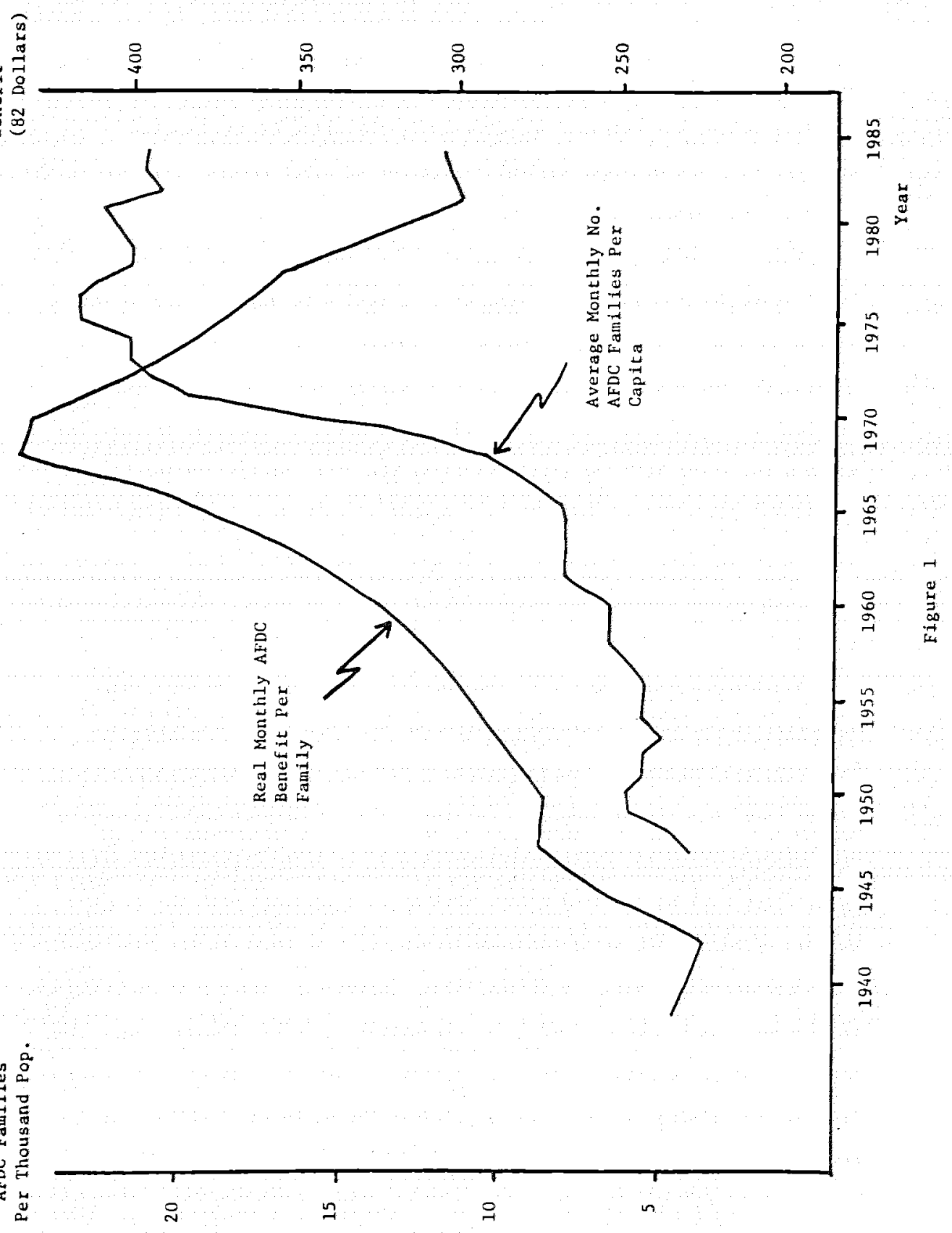


caseload increase. As should be cuite intuitive, and as will be demonstrated formally below, the caseload is effectively the price of the benefit; consequently, the caseioad explosion represented a 300 percent increase in the price of AFDC benefits. ?

This caseload increase suggests that the states may have ailowed real benefits to decline simply in order to keep real AFDC expenditures by the states constant, or at least growing in line with income. However, the benefit decline was more than what was necessary to do so. AkDC expenditures leveled off in the late 1960 s and early 1970 s and then declined in absolute terms after about 1973 , as should be clear from the caseload and benefit trends in Figure 1. A fortiori, AFDC expenditures declined as a fraction of state revenues (more on this momentarily). Whether this should be expected or not depends upon whether the price elasticity of the benefit does or does not exceed one.

Another potential source of the benefit reduction is the well-known zeduction in the growth rate of real income over the 1970s. As shown in Ejgure 2, real income per capita in the U.S. grew during the 1970 s but at a slower rate than in the 1960 s and earlier. Whether this income slowdown is sufficientiy large to explain the benefit decline is an empirical question, of course, and wil be examined below. But it is consistent with the growth pattern of per capita state and local revenues, also shown in the figure, which flattened out markedly in the 1970s. Naturally, along with the slowiown in revenue growth came a slowdown in expenditure growth. Figure 3 shows the trend in the per capita budget surplus, which indirectly reflects expenditure trends. Surprisingly, the budget surplus in the state and local sector actually increased over the 1970s, implying that expenditure growth deciined 
Disposable Income

Per Capita

(B2 Dollars)

\section{Revenues}

Per Capita

(82 Dollars)

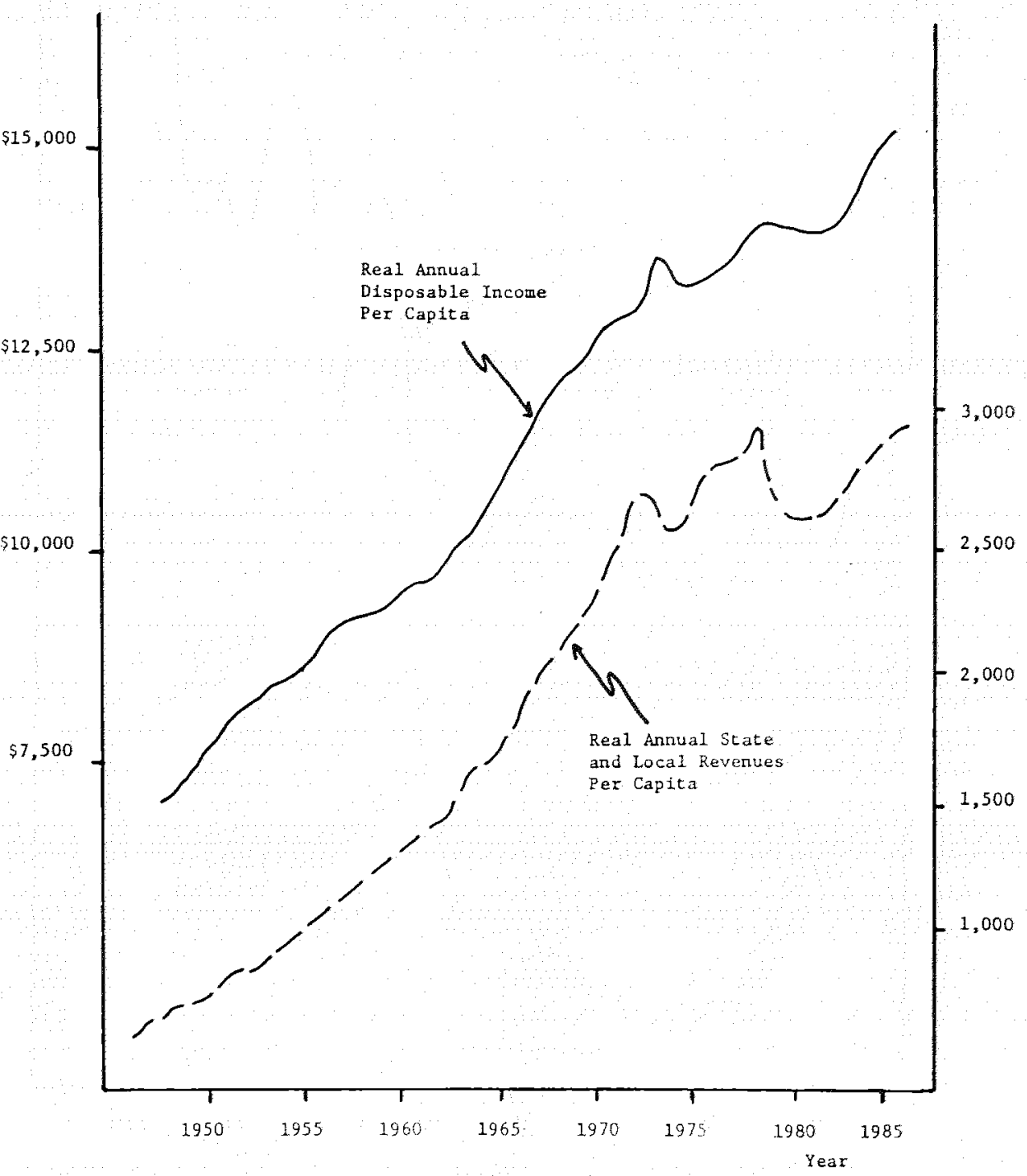

Figure 2 
Surplus ger Capita

(82 Dollars)

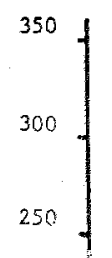

200

150

150

100

50

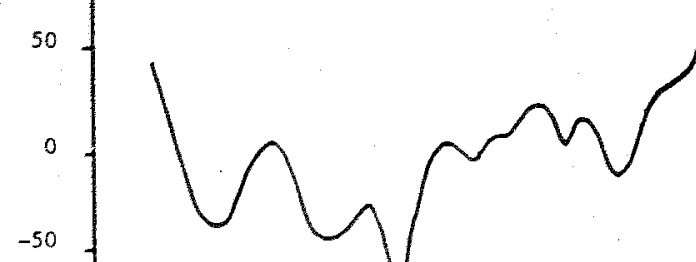

-50
-100

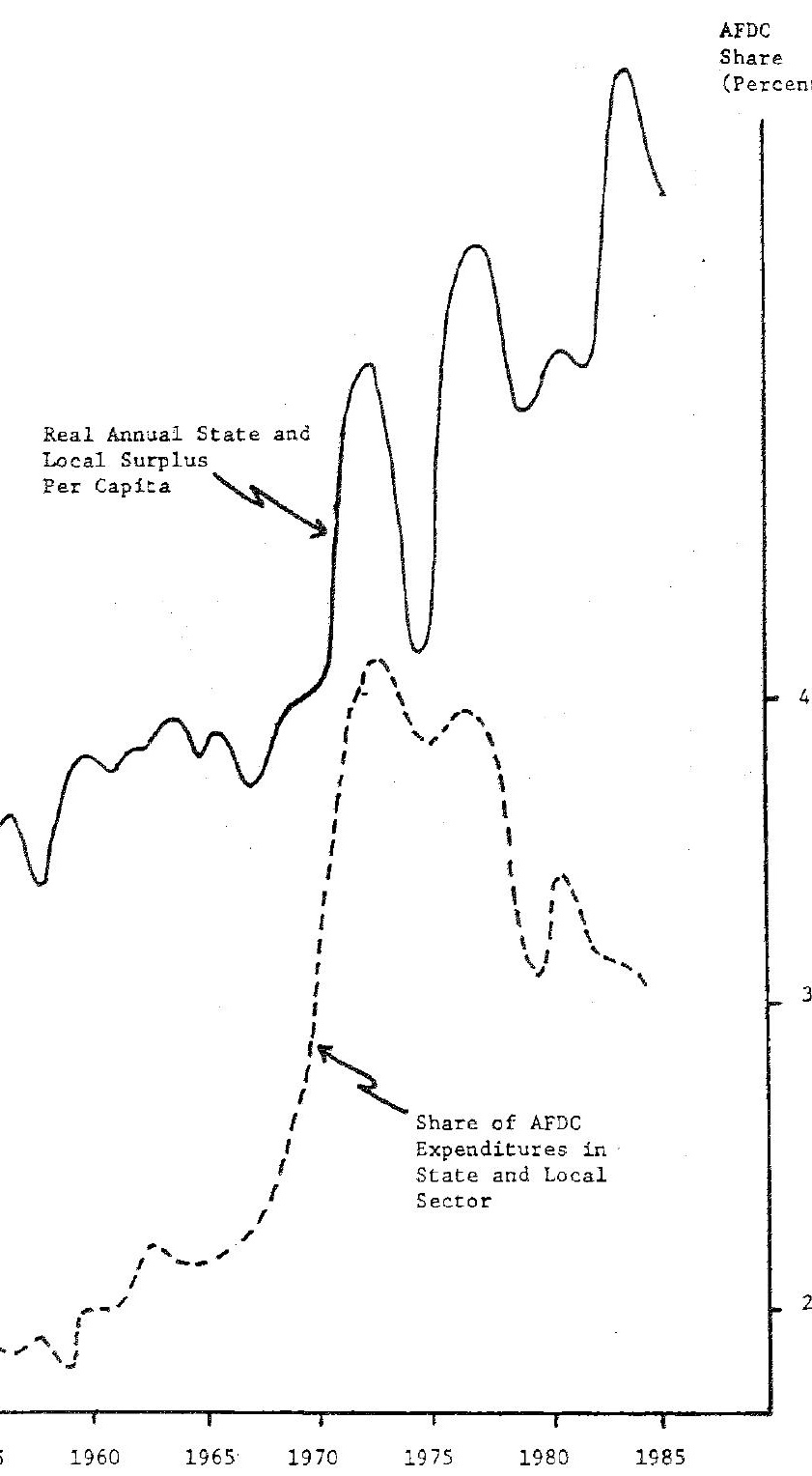

Figure 3 
by more than that of revenues (and that there was no long-term change in "fiscal distress", as it is called in the literature, in that sector). Nevertheless, despite this decline in growth of state and local expenditures, expenditures on AFDC fell even more and even in absolute terms. As a consequence, AFDC expenditures fell as a share of total state and local expenditures, as shown in Figure 3. Thus the decline in the AFDC benefit could not have been wholly a result of general revenue and expenditure decline.

An additional hypothesis for the decline in the AFDC benefit is a reduction in the generosity of federal matching for AFDC benefits. Matching rates for AFDC did indeed decline over the period but the reductions were quite small in absolute terms--from a mean of 58 percent to one of 56 percent for the regular AFDC matching rate and from 62 percent to 59 percent for the Medicaid matching rate. It will require a large price elasticity for these reductions to generate the drastic decline in the AFDC benefit observed. The alternative hypotheses to be examined in detail here are those relating to the possible substitution of non-AFDC benefits for the AEDC benefit. The most prominent source of such effects is the possible substitution of federally-financed Eood stamp benefits for state-financed AFDC benefits. The Food stamp program was introduced in the mid-1960s as an option to the states and grew. slowly until 1974, when Congress mandated that all states implement the program in all their counties. As shown in Table 1 , the AFDC guarantee--the amount actually set by state legislatures--declined rapidly after the introduction of food stamps; in fact, the real AFDC guarantee was 25 percent lower in 1984 than it had been in 1960.2 on the other hand, real food stamp benefits, while fluctuating over the 1970 s and 1980s, have essentially followed no trend and have been approximately 


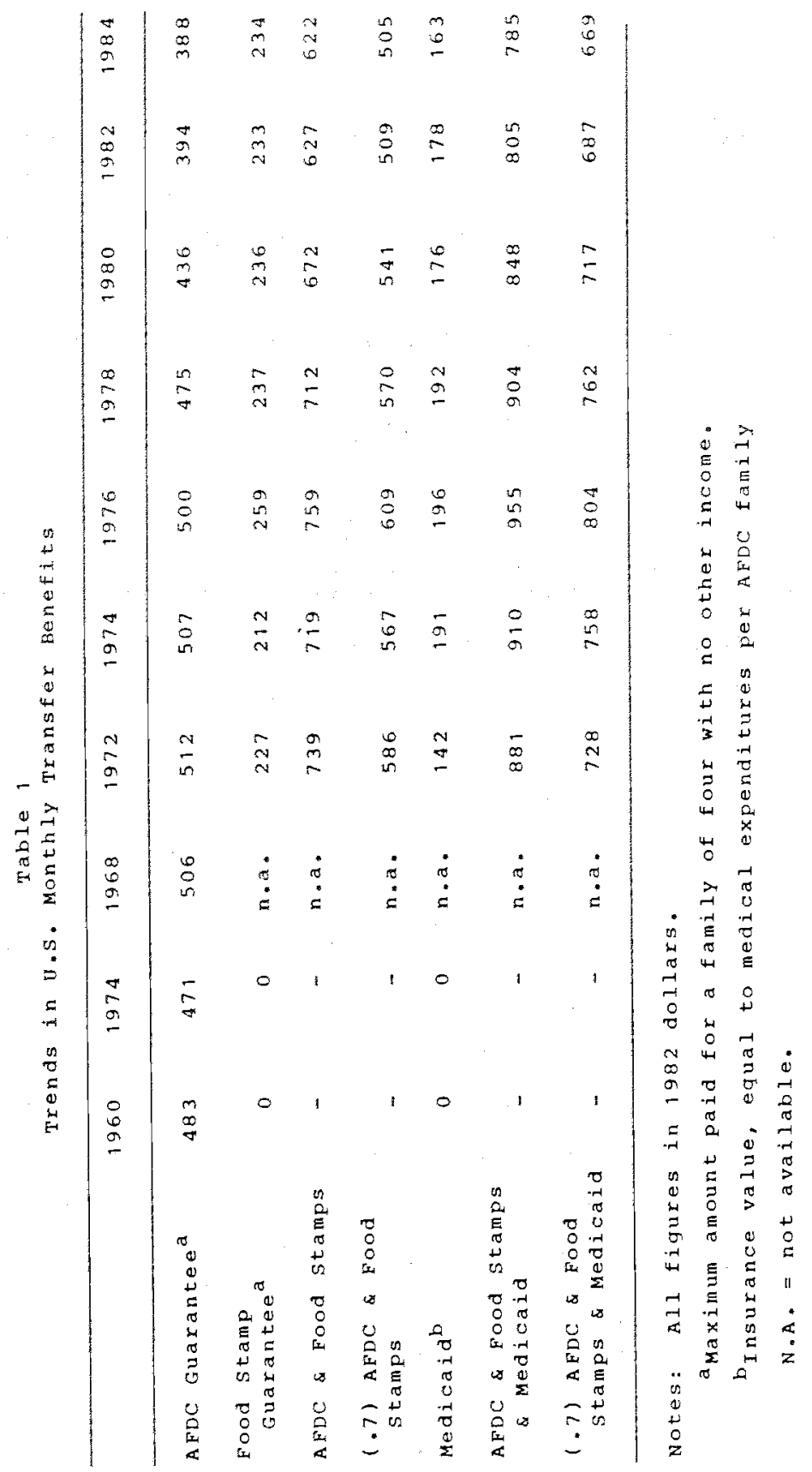


constant, no doubt because they were indexed to inflation by Congress in 1972. In any case, the sum of real AEDC and Food stamp benefits in 1984 was $\$ 622$ per month, almost 30 percent higher than that for AFDC alone in 1960. The hypothesis that states have allowed Food stamps to substitute for AFDC benefits in a one-for-one ratio has several elements supporting it. Eirst, until 1979 AFDC recipients were automatically eligible for Eood Stamps, regardless of income, and hence almost $a: 1$ AEDC recipients received them. Since 1979, when AFDC recipients began to be certified for Food Stamps on the basis of their income and assets, a high proportion have still received them. Second, in most states food stamp certification of AFDC recipients takes place physically in the AFDC offices themselves, providing strong motivation for integration of the prograns. Third, the cash equivalent value of Eood stamps is essentially the same as their market value, making it unlikely that recipients would be worse off by having food transfers substituted for cash transfers.

Nevertheless, the details of the the Food stamp benefit formula imply that simply suming AFDC and Food stamp benefits together is not quite correct. The Food Stamp program taxes AFDC benefits at approximately a 30 percent rate, lowering the net income increment provided by the program by 30 percent of the AEDC anount. Hence, an increase in the AFDC benefit of $\$ 1$ would raise disposable income of the recipient by only 70 cents. As shown in Table 1, the net sum of AFDC and Eood Stamps in 1984 is only $\$ 505$ per month, only 5 percent higher than the value of AFDC alone in 1960." This is a rather small increase over the twenty-four years, given the much higher levels of taxpayer income in 1984. 
This taxation also implies that a reduction in the state AFDC benefit by one dollar would lower the net transfer to female-headed families in the state by only 70 cents. Thus an additional incentive for state legislatures to let the real AFDC berefit decline is provided.

A second source of benefit suostitution that may have occurred is the substitution of Medicaid benefits for AFDC. The Medicaid program was introduced by the U.S. Congress in 1965 and grew rapidly over the late 1960 s and 1970 , at the same time that AFDC benefits were declining. AFDC recipients are categorically eligible for Medicaid benefits so that, even though not all receive medical care in any given time interval, all are essentially covered by health insurance and hence should be thought of as receiving a transfer. As in the AFDC program, state legislatures pay for Medicaid expenditures but they are natched by the federal government at the Medicaid matching rate referred to earlier. However, unlike AFDC, the basic set of medical services provided to recipients is mandated by the federal government. Although states can sipplement the basic set, and can even in some circumstances put restrictions on the basic set $\{$.g.. by limits on hospital days), it is nevertheless the case that the core of Medicaid expenditures are mandated by the federal government and hence are not under the control of the states.

As rable 1 shows, the Medicaid benefit (i.e., its insurance value) grew in the early 1970 s and declined in the later 1970s. The latter decline was the result of sharp increases in medical care inflation and consequent reductions in service delivery. By 1984, the sum of AFDC, Food Stamps and Medicaid was $\$ 785$ per month, over 50 percent greater than the value of AEDC alone in 1960. Taking into account the taxation of AEDC by the Food stamp 
program, the net sum of the three benefits was $\$ 669$ per month in 1984,39 percent higher than the value of AFDC alone in 1960.

A. further source of possible benefit substitution, also related to the Medicaid program, is the substitution of non- oC Medicaid benefits for AFDCrelated benefits. AFDC recipients account for only 25 percent of Medicaid expenditures, the other 75 percent consisting predominately of the aged and the disabled. The average Medicaid benefit for the aged is about double that for AFDC families and that for the disabled is about triple that for AFDC families. The explosion in medical care prices in the 1970 s led to tremendous growth in non-AFDC Medicaid expenditures, particularly for nursing home care. As shown in Figure 4, non-AFDC Medicaid expenditures per capita grew strongly all the way into the late 1970s, until medical care inflation once more generated service reductions. As concerns AFDC benefits, the simple implication is that non-AFDC Medicaid expenditures may have crowded out AFDC Medicaid expenditures and the AFDC benefit itself in the state budget; that is, the two may be substitutes in the state utility function. ${ }^{3}$

Plan of Analysis. The goal of the analysis in the next few sections is to test these substitution hypotheses against the data, and to determine whether the other possible causes of benefit decline (caseload growth, matching rates, real income growth slowdown) are sufficient by thenselves, either alone or in combination, to explain it. The central difficulty in testing the food stamp portion of the hypothesis, which is the primary one, is that the Food Stamp benefit schedule is set by Congress and therefore does not vary across the states. Consequently, no cross-sectional correlation between AFDC and Food stamp benefits can be estimated. 
As with wodel I, a variation can be introduced to allow for rational perception of the taxation of AFDC by the Food stamp program:

\section{Mode I IIA}

$$
\begin{aligned}
\text { Max } U\left(E+\psi F^{\circ}+\phi M, Z\right) \\
\text { s.t. } \quad Y=F(B+Q M)+Z \\
F^{\prime}=F-.3 B
\end{aligned}
$$

which leads to a demand equation under the null of the form:

$$
.7 B+F+M=\alpha+\beta(1.43) P+Y[Y+(1.43) P(F+M)-Q P M]
$$

Finaliy, the influence of non-AFDC Medicaid expenditures can be incorporated by modifying the utility function to allow a third argument representing the transfer to non-AEDC Medicaid recipients, primarily the aged and disabled. A separate argument is required because the marginal utility of transfers to the aged and disabled is likely to be quite different from that of transfers to female heads of family. As noted in the previous section, Medicaid transfers to the aged and disabled are much greater than to female heads, wich could be interpreted as evidence that the marginal utility of transfers to the former are higher than to the latter. 
In past studies of the substitution hypothesis, this difficulty has been circumvented in various ways - orr (1979) conducted a cross-sectional analysis in the mid-1970s and regressed the AFDC benefit on the average Food stamp benefit actually paid in each state. The food stamp benefit actually paid differs across states because of differences in family size, non-welfare income, and the amounts of various deductions in the benefit formula. 4 However, legislatures are well aware of the difference between a guarantee set in a benefit formula--which holds family size, other income, etc. constant-and an actual benefit paid out. In setting the guarantee in the AFDC program, state legislatures typically consider only the guarantee in the Food stamp program in their calculations: In addition, econometrically speaking, identifying the effect of Food stamps by using variation in family size and other variables requires the assumption that those variables do not affect state AFDC actions directly, which is unlikely to be the case. Moreover, the variation in family size and other variables across states is not very large, which could lead to unstable results. A reanalysis of the orr data by fulten et al. (1982) is consistent with this possibility. For Hulten et al. found the Food stamp coefficient in the orr model to be quite sensitive to the inclusion of additional state-specific variables. Finally, regardless of the legitimacy of family size and other such variables as instruments, the cross-sectional variation in the Food stamp benefit they induce is unlikely to have the same effect on the AFDC benefit as will an upward shift in the entire Food stamp schedule, as has occurred over time.

plotnick and winters (1985). (see also Plotnick (1986)) used crosssectional variation in the Food Stamp program in 1971 and 1972 , when the program was not in place in all counties. The food stamp benefit was 
multiplied by the fraction of the counties in the state that had instituted the program. However, as discussed by orr (1979), the states that adopted the program first were the more liberal, high-benefit states; thus the Plotnickwinters variable runs the risk of some degree of endogeneity. on the other hand, Gramlich (1982) used time-series variation in the Food stamp benefit from 1974 to 1981 to estimate the substitution effect. ${ }^{5}$ Gramlich found his results to be quite sensitive to the specification assumed. This is not too surprising for, as Table 1 above shows, the AFDC benefit fell from 1974 to 1981 and the Food Stamp benefit fluctuated with little or no pattern. In fact, given the long-standing decline of the AFDC benefit prior to 1974 and its leveling off after 1981 , it is unlikely that the states were in equilibrium over the 1974-1981 period.

To avoid these difficulties, this study takes a more direct approach to the essentially time-series nature of the hypothesis (i.e., why did AFDC benefits decline over a specific calendar period?) by using cross-sectional AFDC benefit equations estimated prior to the introduction of Food stamps and Medicaid to forecast benefits forward to a period in the future when states had fully adjusted to Food stamps and Medicaid. Pre-1965 benefit regressions are used to forecast the effects of changes in the caseload, matching rates, and state income on the benefit, and comparisons of the forecasted mean benefit and the actual mean benefit are then used to test for structural change in the AFDC benefit equation over time, and hence for the substitution hypothesis. Some backcasts are performed as well by estimating crosssectional regressions in 1984 and backcasting the AFDC benefit to 1960, and some direct pooling across years is conducted to test for structural change directly. This approach thus avoids the requirement of artificially 
generating cross-sectional variation in Food stamps amounts or of having to use AFDC-Food Stamp time-series correlations in the 1970 s to test for substitution.

As a method of testing the weak version of the substitution hypothesis-namely, that there was some substitution though not necessarily on a dollarfor-dollar basis--the approach is rather weak, for it implies that any significant difference between actual and forecasted AFDC benefits be taken as a sign of substitution. Obviously other factors could have been at work. However, as a method of testing the strong version of the hypothesis--that the substitution was actually one-for-one--the approach is correspondingly strong, for it implies that the forecasted AFDC benefit should equal a precise dollar amount. The fact that cross-section regressions generally track time-series variables rather poorly in most past applications strengthens the nature of the test even more, especially when the drastic transformations of the welfare syster in the late 1960 s and early 1970 s are recognized. 
III. MODELING THE EFFECT OF FOOD STAMPS

AND MEDICAID ON AFDC

Since most of the regressions to be estimated will be based upon on 1 y 48 observations, the models must be kept as simple as possible. In the simplest, the median voter of each state allocates his income between expenditure on the AFDC benefit and on other goods, conditional upon a fixed Food stamp benefit provided by the federal government. unfortunately, the data do not contain information on the income or the tax price faced by the median voter, so the mean voter must be used instead as an approximation.

\section{Mode 1 I}

$$
\begin{aligned}
& \operatorname{Max} U(B+\psi F, Z) \\
& \text { s.t. } Y=P B+Z
\end{aligned}
$$

where $B$ is the AFDC guarantee for a fixed family size (e.g., four); $F$ is the Food stamp guarantee for the sane family size; 2 is the per capita amount of some other composite good; $Y$ is per capita income in the state after federal taxes but before state taxes; ${ }^{6}$ and $P$ is the price of the AFDC benefit. $P$ is equal to $(\mathrm{C} / \mathrm{N})(1-\mathrm{s})$, where $\mathrm{C}$ is the AFDC caseload, $\mathrm{N}$ is state population, and $s$ is the federal matching rate for AFDC expenditures. Approximating the solution to the maximization problem for B with a linear demand equation, we have: 


$$
B=\alpha+\beta P+\gamma \tilde{Y}-\psi F
$$

where $\tilde{Y}=Y+\psi P F$ is virtual income, incorporating the income effects arising from the federal gift of Food Stamps. Conventional theory predicts that $\beta<0$ and $Y>0$. Here interest centers on tests of the null hypothesis $\mathrm{H}_{0}: \forall=1$, under which the demand equation simplifies to the Eollowing:

$$
B+F=\alpha+B P+Y(Y+P F)
$$

Thus an increase in. F of $\$ 1$ will. lower. B by $\$ 1$, controling for incone effects. Not controlling for such effects will generate a reduction of B of less than $\$ 1$.

As noted in the previous section, a fully rational voter will realize that the Food Stamp program taxes AFDC benefits, leading to a variation on this model.

Mode 1 IA

$$
\begin{array}{r}
\operatorname{Max} U\left(B+\psi F^{\prime}, Z\right) \\
\text { s.t. } \quad Y=P B+Z \\
E^{\prime}=F-.3 B
\end{array}
$$


which leads to the demand equation

$$
B=(\alpha / \omega)+\left(B / \omega^{2}\right) P+(Y / \omega) \hat{Y}-(\psi / \omega) F
$$

where $\omega=1-.3 \psi$ and $\hat{\Psi}=Y+(\psi / \omega) P F$. Under the null of $\psi=1$, the equation reduces to:

$$
.7 B+F=\alpha+\beta(1.43) p+\gamma[Y+(1.43) P F]
$$

The introduction of the tax rate has, surprisingly, ambiguous effects on the level of the benefit. To illustrate, let $t$ be the tax rate $f t=: 3$ currently). Substitution of $t$ for .3 in (9) and differentiation of (9) w.r.t. the tax rate can be shown to lead to:

$$
\left.\frac{1}{B} \frac{\partial B}{\partial t}\right|_{t=0}=1+\frac{\beta P+Y P F}{B_{0}}
$$

where $B_{0}=a+B P+\gamma(Y+P F)-F$. The price effect $(B<0)$ tends to make the tax effect negative, as is intuitive, but the income effect $(\gamma>0)$ moves it in the opposite direction. Moreover, the benefit increases by one percent from a unit increase in $t$ because the utility function now contains $B(1-t)+F$ as its first argument, implying that the benefit must be increased in order to leave utility at the same level as previously. Perhaps more important for present purposes, the introduction of this tax rate has ambiguous effects on the substitution effect of $F$ on $B$. While the tax rate increases the income effects of $\mathrm{PF}$ in (9), the same multiplicative 
effect of $(1-t)$ on $B$ implies that the reduction in $B$ will be greater than before.

Medicaid benefits can be introduced to this model in a similar fashion, leading to Mode I II.

Mode 1 II

$\operatorname{Max} U(B+\psi F+\phi M, Z)$

$$
\text { s.t. } \quad Y=P(B+Q M)+Z
$$

where $M$ is the insurance value of the Medicaid benefit for AFDC recipients and $Q$ is the relative price of medical care. 7 The resulting demand equation for $B$ can be witten:

$$
B=\alpha+B P+Y \hat{Y}-\psi F-\phi B
$$

where $\tilde{Y}=[Y+P(\psi F+\phi M)-Q P M]$. The income effects in the virtual-income terms are in this case partly negative (-QPM) because the federal "gift" of Medicaid is not free--states must still pay a share. If, in fact, the positive income effects are equal but opposite in sign $(\phi=Q)$, there are no income effects of Medicaid.

Under the null of $\psi=\phi=1$, the demand equation becomes:

$$
B+F+M=\alpha+\beta P+\gamma[Y+P(F+M)-Q P M]
$$


As with wodel I, a variation can be introduced to allow for rational perception of the taxation of AFDC by the Food stamp program:

\section{Mode I IIA}

$$
\begin{aligned}
\text { Max } U\left(E+\psi F^{\circ}+\phi M, Z\right) \\
\text { s.t. } \quad Y=F(B+Q M)+Z \\
F^{\prime}=F-.3 B
\end{aligned}
$$

which leads to a demand equation under the null of the form:

$$
.7 B+F+M=\alpha+\beta(1.43) P+Y[Y+(1.43) P(F+M)-Q P M]
$$

Finaliy, the influence of non-AFDC Medicaid expenditures can be incorporated by modifying the utility function to allow a third argument representing the transfer to non-AEDC Medicaid recipients, primarily the aged and disabled. A separate argument is required because the marginal utility of transfers to the aged and disabled is likely to be quite different from that of transfers to female heads of family. As noted in the previous section, Medicaid transfers to the aged and disabled are much greater than to female heads, wich could be interpreted as evidence that the marginal utility of transfers to the former are higher than to the latter. 


\section{Model II I}

$$
\begin{aligned}
\quad & \operatorname{Max} U\left(B+\psi F+\$ M, M_{H}, Z\right) \\
\text { s.t. } \quad & \quad Y=P(B+Q M)+Q_{N} M_{N}+Z
\end{aligned}
$$

where $M_{N}$ is the medicaid benefit to non-AFDC recipients and ${ }_{N}$ is the price of that benefit, equal to the product of (1-s) and the per capita caseload in the non-AFDC portion of the Medicaid program. 8 The demand equation for $B$ now becomes:

$$
\mathrm{B}=\alpha+\beta P+\delta\left(Q_{\mathrm{P}}\right)+\gamma \hat{\mathrm{Y}}-\psi \mathrm{F}-\phi \mathrm{M}
$$

where $\hat{Y}$ is the same as in equation (13). If Medicaid and non-luedicaid: expenditures are gross substitutes, $\delta>0$, Under the null of $\psi=\phi=1$, the equation becomes: 9

$$
B+E+M=\alpha+B P+\delta\left(Q P_{N}\right)+Y[Y+P(F+M)-Q P M]
$$

Once again, incorporating the taxation of AFDC results in a modification. Without stating the maximization problem, suffice it to state that the demand equation under the null in this case is (Model IIIA):

$$
.7 \mathrm{~B}+\mathrm{F}+\mathrm{M}=\alpha+\beta(1.43) P+\delta\left(\mathrm{QP}_{\mathrm{N}}\right)+\gamma[Y+P(F+M)-Q P M]
$$


Testing the Nulis. As discussed in the last section, the approach taken here to testing the nulls of dollar-for-dollar substitution is based upon forecasts from cross-section regressions for $B$ estimated prior to the introduction of Food stamps and Medicaid. The earliest year for which the AEDC guarantee for a family of four is available is 1960 and the latest year for which it and the independent variables are available is 1984 . Both years can be reasonably argued to be equilibrium years, for in 1960 the AFDC system had been stable in structure and in caseload growth for over a decade and in 1984 the AFDC benefit appears to have settled down after the transitional years in the $1970 \mathrm{~s} .10$ Thus cross-sectional regressions of $B$ on $P$ and $Y$ in 1960 can be used to forecast the AFDC benefit under Models I-II to 1984 , and significance tests can be conducted on the difference between the forecasted and actual mean AFDC benefit (Model III cannot be estimated on 1960 data because data on $P_{N}$ are unavailable then). Such tests will indirectly determine the extent to which changes in the level of the caseload, matching rates, and disposable income between the years are capable of explaining the benefit decline.

This test is a very strong one because it does not utilize information in 1984, and because it therefore tests the joint null of $\psi=\phi=1$ and of no structural change in the equation. It is implicitly a test of the rational expectations forecast under the null of dollar-for-dollar substitution. A statistically symmetrical alternative is to conduct a set of tests by estimating Models I-III on the 1984 cross-section and by using them to backcast the 1960 benefit. Such estimates obviously incorporate different information, particularly that on Medicaid, and Model III can be estimated. 
Conditional upon the outcome of this analysis, an obvious further set of tests can be conducted by pooling the two years and testing directly for structural change in the parameters, thereby using all the statistical information in the data.

The means of the variables used in the analysis are shown in Table 2.11 As noted previously, the mean AFDC guarantee fell markedly between 1960 and 1984, but Food Stamps and Medicaid outweighed the AFDC decline. The caseload more than tripled, leading to a large effective price increase. ${ }^{12}$ The matching rate appears to have increased over the period, but this is a result of the nonlinearity of the matching schedule in 1960, to be discussed momentarily. Real disposable income about doubled from 1960 to 1984 . Although standard exrors are not shown, the data reveal that the addition of Food stamps has lowered the cross-stats variance in transfers but Medicaid has raised it back to the same level as that of AFDC alone.

The nonlinearity of the matching rate schedule in 1960 requires modifying the estimation procedure for the estimates in that year. 13 In 1960 the federal government matched state AFDC expenditures at a 83 percent rate at low benefit levels, at a state-specific "federal" matching rate at medium benefit levels (the mean of which is shown in Table 2), and at zero rates for high benefit levels. As is well known from the analysis of piecewise-linear budget sets (Hausman, 1985; Moffitt, 1986), the demand equation along each segment in 1960 can be written in this case as

$$
B=a+\hat{B P}+\gamma \tilde{Y}
$$


Table 2

Means of the Variables Used
in the Analysis

1960

1984

\begin{tabular}{lcc}
\hline $\mathrm{B}$ & 465 & 344 \\
$\mathrm{M}$ & 0 & 242 \\
$\mathrm{C} / \mathrm{N}^{\mathrm{a}, \mathrm{c}}$ & 0 & 185 \\
$\mathrm{~s}^{\mathrm{b}}$ & 13.8 & 42.8 \\
$\mathrm{P}^{\mathrm{C}}$ & 57.9 & 59.6 \\
$\mathrm{Y}^{\mathrm{N}}$ & 5.6 & 17.6 \\
$\mathrm{Q}_{\mathrm{N}}^{\mathrm{a}, \mathrm{C}}$ & 5719 & 185 \\
$\mathrm{OP}_{\mathrm{N}}^{\mathrm{C}}$ & $-\mathrm{d}$ & 1.14 \\
\hline
\end{tabular}

Notes:

Data Sources: See Appendix B. $\mathrm{N}=48$

All dollar figures in 1982 dollars.

acaseload lagged 3 years.

bMultiplied by 100 .

cMultiplied by 1000 .

dot required for analysis. 
where $\tilde{P}$ and $\tilde{Y}$ are, respectively, virtual price and income on a segment. Their definitions are straightforward and are not written out for brevity. Monte Carlo evidence incicates that oLs estimates of $(24)$ can give extremely biased estimates of the effects of grants-in-aid (Megdal, 1987), for $\tilde{P}$ and $\tilde{Y}$ are endogenous. Although the most efficient method of estimation of such models is maximum likelihood (see moffitt, 1984, for an application to grants-in-aid), the main analysis presented below will instead use the instrumental variable technique of evaluating the schedule at the mean benefit for all observations. The mean benefit in 1960 was in the middle segment of the schedule with matching rate shown in Table 2 . The implied virtual price and income are therefore used in all 1960 regressions. To test the sensitivity of the results to this procedure, maximum likelihood piecewise linear constraint (PLC) estimates are obtained as well on a subset of the models. 


\section{MAIN RESULTS}

Table 3 shows the results of estimating the 1960 AFDC benefit equations. Column (1), the simplest model, shows a significant and positive income effect and a negative, though insignificant, price effect. At the means of the data the coefficients imply price and income elasticities of -.17 and 98 , respectively. The near-unity income elasticity implies that the share of income devoted to AFDC should stay approximately constant as income increases.

Columns (2) and (3) show the effects of entering additional state variables for region, urbanization, educational level of the population, and other factors. Region appears to be moderately important in explaining benefits, with the south showing the lowest benefits, as expected, and the West and Northeast showing the highest. However, neither the urbanization variables nor the variables added in column (3) are very significant, and an E-test strongly rejects the significance of the incremental variables in that column. Perhaps more important for present purposes, the inclusion of these variables has no quantitatively important effect on the income coefficient but it does reduce the magnitude of the price effects greatly and renders them completely insignificant. Thus the 1960 data provide weak evidence of price effects at best.

Forecasts to 1984 are shown in Table 4 for Models I and II (Model III cannot be forecasted because no estimate of the parameter $\delta$ is possible 
Table 3

1960 Benefit Regressions

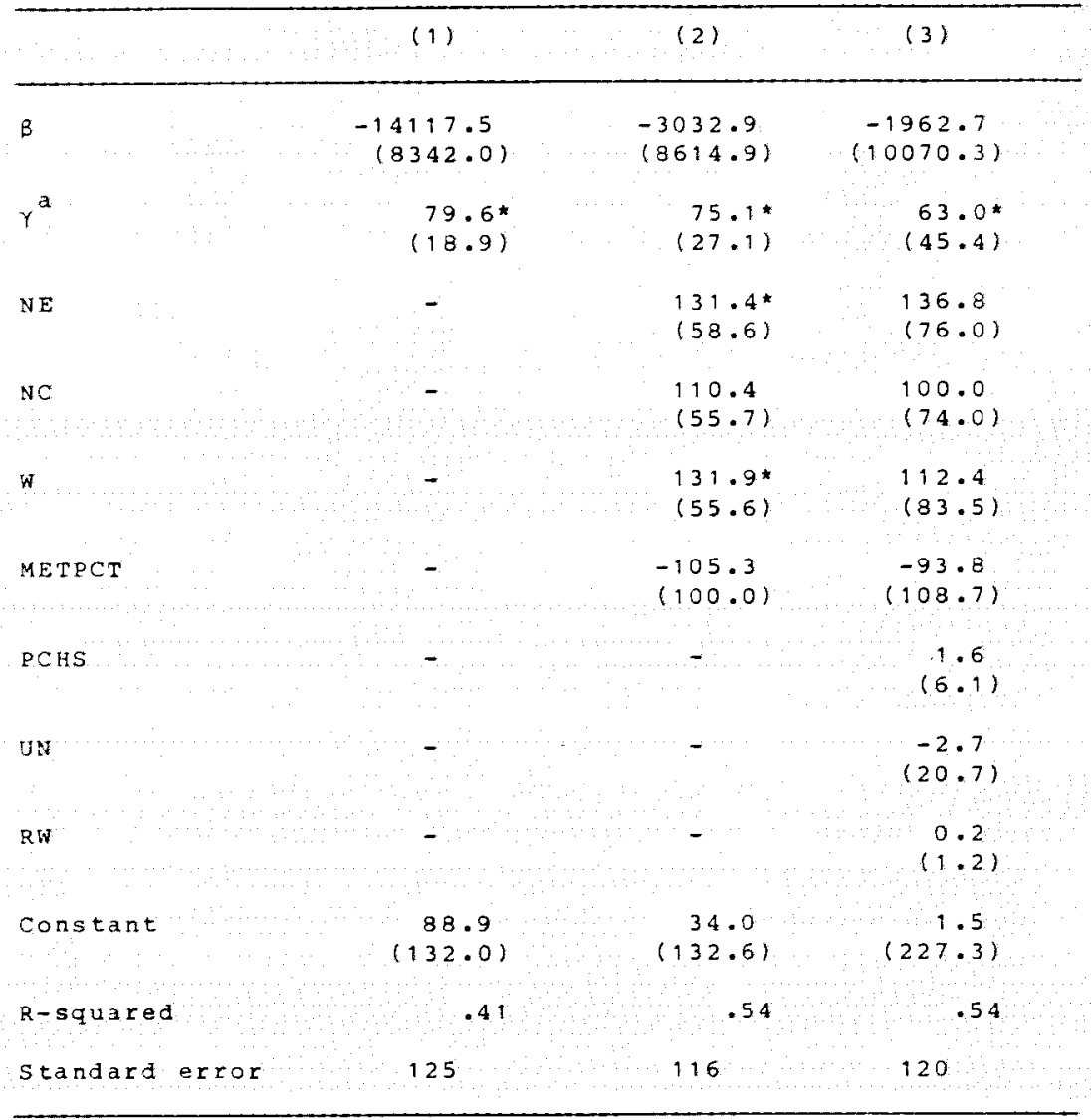

Notes:

standard errors.in parentheses.

* : Significant at 5 percent level.

amultiplied by 1000 .

Variable definitions: NE, NC, W are regional dumies for Northeast, North Central, and West, respectively (South omitted); METPCT = percent of state population in metropolitan areas; PCHS = percent of population with a high school degree; UN = state unemployment rate; $R W=$ rea 1 weekly manufacturing wage. Means given in Appendix Table C -1 . 


\section{Mode I I}

$$
\begin{aligned}
& \text { Actual } B+F \\
& \text { Forecast } B+F \\
& \text { Forecast error } \\
& \text { F-statistic } \\
& \text { (p-value) }
\end{aligned}
$$

585

645

60

.15

$(.70)$

standard error

ModeI IA

Actual .7B+F

482

Forecast $.7 \mathrm{~B}+\mathrm{F}$

537

Forecast error

F-statistic

$$
\text { ( } p \text {-value) }
$$

\section{Model II}

$$
\begin{aligned}
& \text { Actual } B+F+M \\
& \text { Forecast } B+F+M \\
& \text { Forecast error } \\
& \text { F-statistic } \\
& \text { (p-value) }
\end{aligned}
$$$$
770
$$$$
-125
$$

\section{Mode I IIA}

$$
\begin{aligned}
& \text { Actual } \cdot 7 B+F+M \\
& \text { Forecast } \cdot 7 B+F+M \\
& \text { Forecast error } \\
& \text { F-statistic } \\
& \text { (p-value) } \\
& \text { Standard error }
\end{aligned}
$$$$
667
$$$$
537
$$$$
-130
$$ 
with the 1960 data). Ali forecasts use the coefficients in column (1) in Table 3.14 The forecasted benefit in 1984 is $\$ 645$ per month, far above the actual AEDC benefit of $\$ 344$. But this forecast is on $1 y \$ 60$ above the sum of AFDC and Food stamps in 1984, a very close forecast. The forecast is insignificantly different from the actual value, though this is partly a result of a fairly high standard error of the prediction (\$156). The forecast of the model under the assumption that voters recognize the taxation of AFDC by the Food Stamp program (Model IA) is quite similar, overpredicting the net benefit sum by approximately $\$ 55$, again insignificantly different from zero. When used to predict for models including Medicaid (Models II and IIA), the 1960 regressions underpredict because the Medicaid benefit is about $\$ 180$. The forecast error ranges from $\$ 125$ to $\$ 130$ but is again insignificantly different from zero:

These 1960-based forecasts provide considerable support for the full substitution hypothesis, for the forecasts are fairly close given the major changes that occurred in the system between 1960 and 1984 , and given the fairly large absolute magnitude of the implied increase in the benefit sum between the years. Even for Modal II, for example, the implied increase in the benefit $s$ um is $\$ 305(\$ 770-\$ 465)$, and the 1960 regression predicts twothirds of that increase.

The estimates of Models I-III on the 1984 data are presented in Table 5.15 The results are for the most part quite similar to those in 1960. Price effects, though negative, are on the borderline of significance at conventional levels in most of the models. Even in those models (IIA and IIIA) where price effects are significant, the implied elasticities are quite 


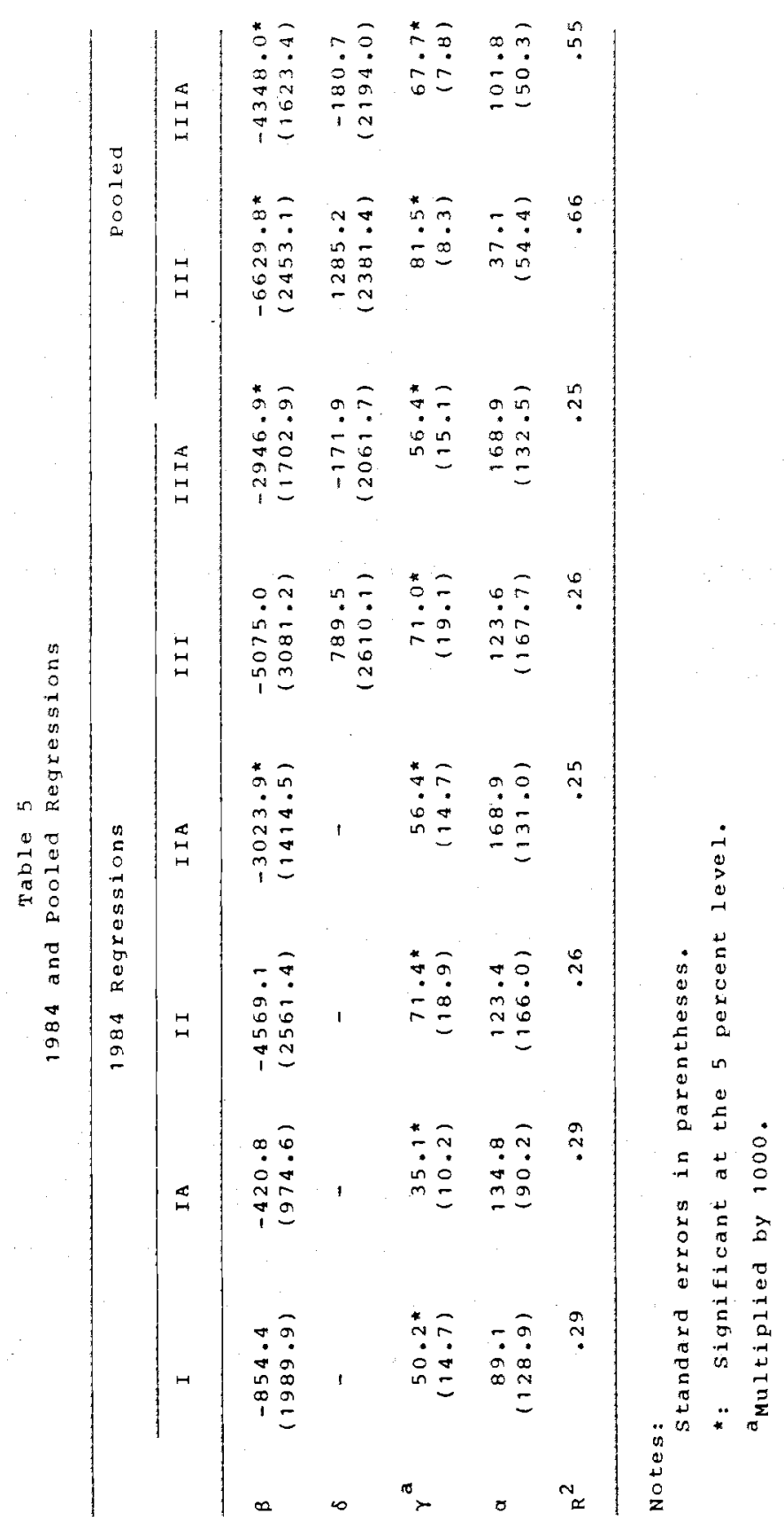


low (about 12 percent). Income effects, on the other hand, are positive and significant in all models. The implied elasticities center around .94, once again quite close to unity and therefore again implying constant shares with respect to income. The effect of non-AFDC expenditures, shown in the estimates for Model III, are completely insignificant, thus indicating no substitutability between the expenditures of the two programs. Backcasts to 1960 using the coefficients for each model separately are shown in Table 6. The Eorecast errors in general are once again very small, especially so for the models including Medicaid. Whereas Models I and IA underpredict the 1960 AFDC benefit by $\$ 94$ to $\$ 132$, Models II, IIA, III, and IIIA overpredict by no more than $\$ 41$. The best models for prediction are those which assume rational voters that take account of both Medicaid and the taxation of AFDC by the Food Stamp program (Models IIA and IIIA), models which predict the AFDC benefit to be only $\$ 9-\$ 10$ over its actual value! Moreover, the F-statistics reject Models I and IA most strongly, and they favor wodels IIA and IIIA the most. The standard errors of the estimates are quite small for all equations. The 1984 equations are thus even more supportive of the full substitution hypothesis than those for 1960 , especially for the Eull rationality models.

Estimates for Models III and IIIA, the most complete models, obtained by pooling the 1960 and 1984 data are shown in the last two column of Table 5. 16 price effects are negative and imply elasticities at the mean of about -12 percent, and income effects are once again positive and significant, implying income elasticities of about 1.06 . An F-test for similarity of the coefficients overwelmingly fails to reject the null of no structural change 


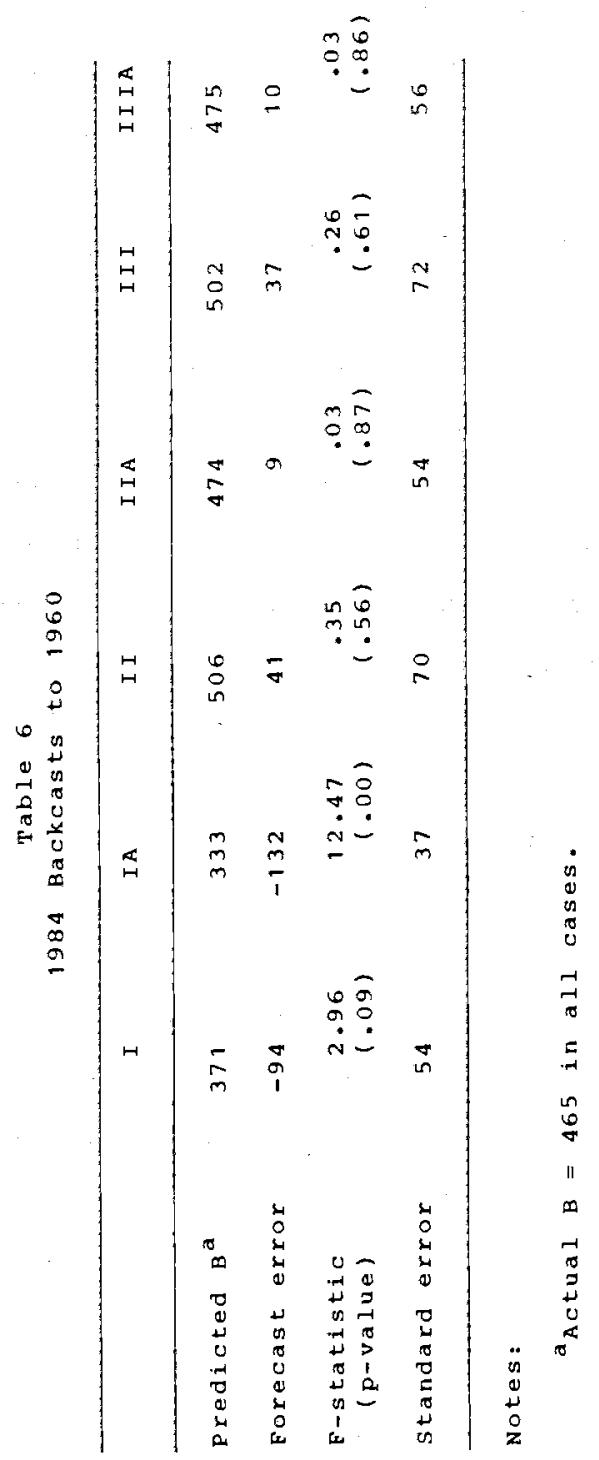


(F-statistics of .39 and 1.2 in Models II and IIIA, respectively). Thus the use of all the information at hand again strongly supports the full substitution hypothesis.

Taking the pooled estimates for Model III as valid, the sources of the increase in the benefit sum from $\$ 465$ to $\$ 770$ between 1960 and 1984 can be deduced. Using the means for the variables indicates that the increase in price pushed down the benefit by $\$ 80$ but that the increase in disposable income pushed it up by $\$ 364$, the residual (\$19) accounted for by the introduction of the non-AFDC Medicaid program. The relatively weak effect of the caseload explosion in the late 1960 s and early 1970 s in pushing down the benefit is consistent with the consistently weak price elasticities estimated in both the 1960 and 998 data. Thus the bulk of the evidence clearly supports an interpretation that income increases over the past three decades have indeed increased the transfer to female heads, and that the decline in the AFDC benefit is virtually entirely a result of the substitution of Food Stamps and Medicaid.

PLC Estimates: To test the sensitivity of the estimates to the instrumental variable procedure used to address the piecewise-linearity of the 1960 matching rate formula, the Eull maximum likelihood PLC model was estimated on the 1960 data and on the pooled 1960-1984 data for Models III and IIIA. The exact specification of the model is given in Appendix A along with the definition of the log Iikelinood function.

The results are shown in Table 7. The first column shows the 1960 estimates, which appear to be moderately close to those in Table 3 lat least given some of the large standard errors in both equations) but are not quite 
Table 7

Maximum Likelihood PLC Estimates

1960, 1984 Fooled

$\$ 960$

Model III ModeI IIA

\begin{tabular}{|c|c|c|c|}
\hline 8 & $\begin{array}{l}-5513.5 * \\
(2869.7)\end{array}$ & $\begin{array}{l}-5267.7 * \\
(1660.1)\end{array}$ & $\begin{array}{l}-3986.7 * \\
(1397.4)\end{array}$ \\
\hline$\gamma^{a}$ & $\left(\begin{array}{l}71 \cdot 3^{*} \\
(22.0)\end{array}\right.$ & $\begin{array}{l}70.7 * \\
(9.7)\end{array}$ & $\begin{array}{l}59.1 * \\
(8.2)\end{array}$ \\
\hline$\delta$ & -- & $\begin{array}{c}813.6 \\
(2688.7)\end{array}$ & $\begin{array}{c}-240.6 \\
(2556.6)\end{array}$ \\
\hline$\alpha$ & $\begin{array}{l}132 \cdot 2 \\
(153.1)\end{array}$ & $\begin{array}{l}131.3 \\
(74.4)\end{array}$ & $\begin{array}{l}174.8^{*} \\
(60.1)\end{array}$ \\
\hline$\sigma_{E}$ & $\begin{array}{l}123.1 * \\
(17.6)\end{array}$ & $\begin{array}{l}126.4^{*} \\
(10.8)\end{array}$ & $\begin{array}{l}114.3 * \\
(10.6)\end{array}$ \\
\hline$\sigma_{v}$ & $\begin{array}{c}10.4 \\
(13.0)\end{array}$ & $\begin{array}{c}10 \cdot 5 \\
(13 \cdot 3)\end{array}$ & $\begin{array}{c}9.4 \\
(14.9)\end{array}$ \\
\hline $\begin{array}{l}\text { Log Likelihood } \\
\text { Unrestricted } \\
\text { Log Likelihood }\end{array}$ & -297.6 & -599.47 & -590.09 \\
\hline
\end{tabular}

Notes: Standard errors in parentheses.

* Significant at 10-percent level.

${ }^{a}$ Multiplied by 1000 .

ballows separate coefficients for 1968 and 1984 . 
the same. The second and third columns of Table 7 show the estimates of Models III and IIIA, respectively, on the pooled 1960-1984 data. The estimates in this case are very close to those in the corresponding columns of Table 5 and; consequently, generate the same types of backcasts shown in Table 6. Moreover, tests for a change in structure between the years-obtainable from the unrestricted $\log$ likelihoods shown in the table--are strongly rejected (chi-squared statistics of .04 and 2.48 in the two equations, respectively). Thus the instrumental variable procedure used in the previous sections appears to have generated sufficiently good estimates as to allow all the conclusions reached previously to be retained.

Effects of Federal Matching. Given the primary result of the analysis-that lump-sum federal transfers appear to generate dollar-for-dollar displacement by the states-it should be of interest to determine whether traditional federal matching for AFDC may be an alternative mechanism to increase transfers by the states. As is well-known, the efficacy of matching in general depends upon the magnitude of price elasticities and, relatedly, on the degree to which federal grants are substituted into other areas of expenditure by the states. The fraction of the AFDC grant substituted into other areas of expenditure is calculated as one minus the ratio of the stimulus (i.e., the effect of matching on the AFDC benefit) to the federal grant.

In a prior analysis (Moffitt, 1984), it was found that almost 80 percent of federal AFDC grants in 1970 were spent on non-AFDC purposes, implying that federal matching stimulates relatively little additional AFDC expenditure by 
the states. A similar calculation here implies that out-substitution was 85 percent in 1960 but only 38 percent in $1984 .^{17}$ The much lower outsubstitution effect in 1984 is a result of two Eactors. First, the caseload tripled between 1960 and 1984; therefore, a given federal matching rate has a much greater stimulative effect on the AFDC benefit than it did previousiy. Second, the mean federal grant has fallan because the mean benefit has fallen, thereby again lowering the percent substituted out. Thus it appears that, currently, almost two-thirds of the federal AFDC grant is indeed used to increase state AFDC expenditures, making this strategy considerably more attractive than using Food stamps to increase the total transfer. 18 


\section{EFFECTS ON THE AFDCU PROGRAM}

The AFDCU program is a supplement to the regular AFDC program and provides benefits to low-income families even if an able-bodied male is present in the household. Eligibility for such families is based not only upon the usual income and asset conditions in the regular AEDC program but also upon whether the male is unemployed and has had a history of sufficiently strong attachment to the labor force. The AFDCU program was enacted by Congress and made optional to the states in 1961, with matching set at the same rate as that for the regular AFDC program. However, while the number of states adopting the program rose quickly in the early 1960s, it leveled off at around 50 percent in the late 1960 s and has remained approximately at that level since.

The Food Stamp supplementation hypothesis explored in the last section. would appear to be of relevance to the growth of AFDCU as well. The Food Stamp program is notable in the U.S. transfer system for its provision of benefits to husband-wife families, unlike the regular AEDC program, and hence the Food stamp program is closer to being a universal transfer program than any other in the U.S. However, the provision of federally-funded benefits to husband-wife families, the same group covered by the AFDCU program, may, by a similar logic to that discussed for the regular AFDC program, have discouraged: the adoption of AFDCU program in the states. It should be noted that AFDC benefits to female-headed families and to husband-wife families are required to be the same for equivalent family sizes and other circumstances, so no 
leeway is possible to lower the benefit in the AEDCu program separately from that in the AFDC program; the only decision is to adopt or not to adopt. A simple model that captures the najor factors influencing the AFDCU adoption decision is as follows.

\section{Model IV}

$\operatorname{Max} U(B+\theta D B, z)$

$$
\text { s.t. } Y=\left(P_{1}+D P_{2}\right) B+Z
$$

where $B$ is the common benefit for AFDC and AFDCU families, $D$ is a dumy variable equal to one if the state adopts $A F D C U$ and $O$ if not, and $P_{1}$ and $\mathrm{P}_{2}$ are the prices for the AFDC and AFDCU programs, respectively (caseload times own-payment share). The parameter $\theta$ measures the marginal utility of transfers to husband-wife couples. The solution to the maximization problem can be written as follows:

$$
\begin{array}{ll}
B=\frac{\alpha}{1+\theta}+\frac{B}{(1+\theta)^{2}} P_{T}+\frac{Y}{(1+\theta)} Y \text { if } D=1 \\
B=\alpha+\beta P_{1}+Y Y & \text { if } D=0 \\
D=1 \text { if } D^{*}>0 ; D=0 \text { if } D^{*}<0 \\
D^{*}=V\left[\frac{P_{T}}{1+\theta}, Y\right]-V\left[P_{1}, Y\right]
\end{array}
$$


where $P_{T}=P_{1}+P_{2}$ is the total price if AFDCU is adopted (total per capita caseload times own payment share) and $V[P, Y]$ is the indirect utility function.

Our interest here is less in the benefit equations than in the AFDCU choice equation (30). 19 The interesting implication of (30) is that AFDCU is chosen iff $\left[P_{T} /(1+\theta)\right]<P_{P}$, or

$$
D=1 \text { iff } \theta>\left(P_{2} / P_{1}\right)
$$

Since $P_{1}$ and $P_{2}$ are both per capita caseloads times one minus identical matching rates, we can say that AfDCu is adopted only if the marginal utility of transferring funds to husband-wife families is greater than the ratio of the husband-wife caseload to the regular female-head caseload. This result impiles that increases in the regular AFDC caseload and decreases in the actual or potential AfDCU caseload raise the probability of adopting AFDCU, both of which are testabie implications.

The criterion in (31) is notable for its implication that the income level of the state has no effect on the probability of adopting AFDCU. This would seem contrary to any notion of AFOCU, and transfers to husband-wife families in general, as normal goods. Clearly this property of (31) is a result of the specification of the utility function and the linear indifference curves between the benefits to female-headed families and husband-wife families, a restriction which may be violated. However, this restriction does make the model in (25)-(26) testable by simply determining whether income does or does not affect AFDCJ adoption probabilities independent of $P_{1}$ and $P_{2} \cdot 20$ 
Incorporating Food stamps in a manner similar to that in the last section, we have

Mode $1 \mathrm{~V}$

$$
\operatorname{Max} U\left[B+8 D B+\psi_{1} F+\psi_{2} \theta F, z\right]
$$

with the budget constraint as in (26). Note that Food stamps are provided to husband-wife families regardless of whether the state has adopted an AFUcU program. Under the null of $\psi_{1}=\psi_{2}=1$, the demand equations are the following:

$$
\begin{aligned}
B+F & =\frac{\alpha}{1+\theta}+\frac{\beta}{(1+\theta)^{2}} P_{T}+\frac{\gamma}{1+\theta}\left[Y+P_{T} F\right] \text { if } D=1 \\
B+F & =\alpha+\beta P_{1}+Y\left[Y+P_{1}(1+\theta) F\right]-\theta F \text { if } D=0 \\
D^{*} & =V\left[\frac{P_{T}}{1+\theta}, Y+P_{T} F\right]-V\left[P_{1}, Y+P_{1}(1+\theta) F\right]
\end{aligned}
$$

Here the demand equations for benefits (33) and (34) imply that the Eood stamp program lowers the AFDC benefit in non-AFDCU states more than in AFDCU states, at least ignoring income effects, as a result of the term $-\theta F$ in (34). The source of this effect is simply that non-AFDCU states are initially providing nothing to husband-wife families at all, and hence the introduction of Food Stamps has an overly strong substitution effect on the AFDC benefit. 
More important for present purposes, equation (35) implies that, contrary to expectations, the AFOCU adoption decision is actually independent of the Food Stamp benefit, aside from income effects. The latter are certain to be insignificant, as the increase in virtual income created by the Eood stamp program is about one-tenth of one percent of income. Thus the AfDcu criterion function is essentially equivalent to that in the prior model, as given by (3t)-only relative prices matter. The independence of the AFDCU decision from the Eood stamp benefit again arises from the Iinear indifference curves in the particular utility function postulated, and is once again empirically testable.

A modification to incorporate Medicaid benefits leaves the model virtually unchanged.

Model VI

$$
\begin{aligned}
& \operatorname{Max} U[(B+M)(1+\theta D)+F(1+\theta), Z] \\
& \text { s.t. } Y=\left(P_{q}+D P_{2}\right)(B+Q M)+Z
\end{aligned}
$$

under the null of Eull substitution of Medicaid and Food stamps for AFDC. Note that the provision of Medicaid benefits is tied to the provision of AFDCU, for husband-wife families are generally eligible for Medicaid on $1 y$ if they are AFDC recipients. The criterion function for AEDCU adoption is the following: 


$$
\begin{aligned}
D^{*}= & V\left[\frac{P_{T}}{T+\theta}, Y+P_{T}(F+M)+P_{\left.T^{2 M}\right]}\right. \\
& -V\left[P_{1}, Y+P_{1}(F(1+\theta)+M)-P_{1} Q M\right]
\end{aligned}
$$

Ignoring income effects, which will be trivial, the criterion function for AFDCU adoption is once again the same as that in (31).

Econometric Tests. To test the various hypotheses implied by the model, a before-and-after strategy similar to that in the last section is taken. The "pre" year is, in this case, taken to be 1968. The year 1960 is not appropriate because AFDCU was not available at that date, and eariier dates are too close to 1961 to have allowed the slower-acting states to adopt the program if they so desired. The "post" year is again taken as 1984 , the latest year for which all data are available. In 196844 percent of the states had adopted AFDCU and in 198448 percent had; thus there was virtually no change between the two dates.

At each year, probit equations for AFDCU adoption are estimated using as independent variables the regular AFDC price variable $\left(P_{1}\right)$, evaluated in 1968 on the mean segment, and proxies for the AFDCU caseload. Since the AFDCU caseload is observed only for states actually adopting the program, standara selectivity bias problems would arise if caseload data were directly used. Two proxy variables are employed instead: (1) the male unemployment rate in the state, assumed to be positively related to the actual or potential AFDCu caseload, and (2) the real weekly manufacturing wage in the state most workers in manufacturing are male), taken to be inversely related to the 
actual or potential AEDCU caseload. Other variables that may be of interest (male wage rates, earnings, etc.) are not available. The means of the variables for the two years are shown in Appendix Table C-2.

Table 8 shows the results of the probit exercises. Column (1) shows a probit equation estimated on the 1968 data alone. The price of the regular AFDC caseload has a strong and significant positive effect on the AFDCU probability, as predicted by the models. The magnitude of the coefficient implies that a ten-percent increase in the AFDC price increases the adoption probability by 9 percentage points at the mean. The manufacturing wage and the male unemployment rate both have the expected signs--increases in male wages and decreases in male unemployment make the cost of adoption lower--but both effects are weak statistically, largely a result of the small sample sizes. The state income variable is also included and, interesting, is positive but insignificant, implying that income may have no effect independent of the prices of AEDC anc AFDCU benefits. Thus there is tentative support for the model in the 1968 data.

Columns (2) and (3) show results obtained by pooling the 1968 and 1984 observations. 21 Column (2) shows that the price and income variables retain their same signs and significance levels in the pooled data, but a duny for 1984 is strongly significant and negative. test for a change in the parameters other than the intercept from 1968 to 1984 was rejected, but the significant change in the intercept is consistent with a substitution effect of the Food Stamp program and hence inconsistent with the restrictive parameterization of the utility functions in Models IV-VI. The source of the downward shift in AFDCU probabilities is primarily the strong increase in the 
Table 8

AFDCU Rrobit Regressions

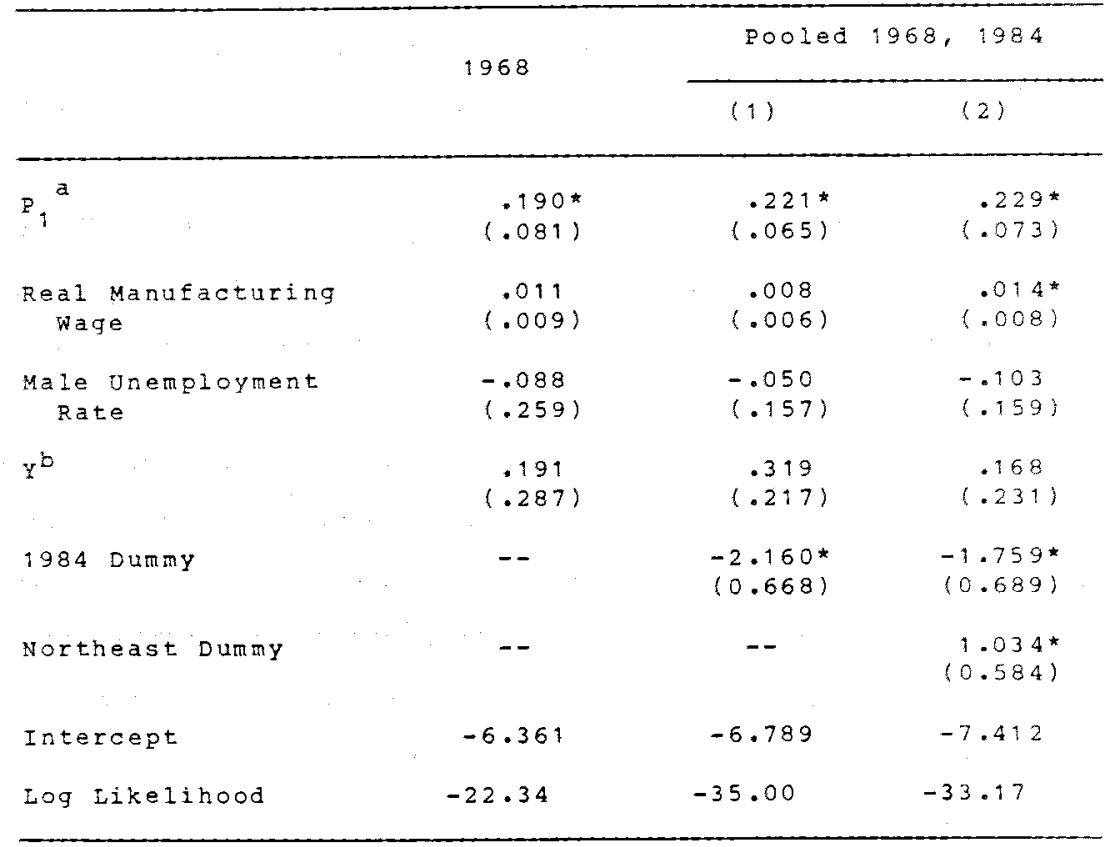

Notes:

Standard errors in parentheses.

*: Significant at 10 percent level.

avariable multiplied by 1000 .

bvariable divided by 1000 . 
caseload over the 1970s, which, according to the strong and positive caseload effects, should have generated an increase in AFDCU adoption from 1968 to 1984. The failuxe of the fraction of states adopting the program to grow past the late $1960 s--a b o u t$ the time Food stamps were introduced--is thus attributed. in the regression to the intercept and hence to a structural shift downard. Since AFDCU is commly strongly associated with the northeastern industrial states, which also have high caseloads, column (3) reports the results of adding a regional dumy for the Northeast. The addition of the dumy does reduce the magnitude of the downard structural shift, though it remains significant. However, the caseload effect is unchanged and the effects of manufacturing wages and male unemployment rates increase in both magnitude and significance, thus strengthening their support of the relevant hypotheses. 


\section{SUMMARY AND IMPLICATIONS}

This study has examined the causes of the decline in real AFDC berefits over the 1970 s and 1980 s and has focused on testing the hypothesis that states have allowed Food Stamps and Medicaid to substitute for AFDC in the total benefit package provided to Eemale heads in the U.S. The analysis is conducted by forecasting benefits in the 1980 s from cross-section regressions in the 1960 s, backcasting benefits in the 1960 s from cross-section regressions in the $1980 \mathrm{~s}$, and pooling data from both periods to test directly for structural change. The results support the strong version of the substitution hypothesis, that for which substitution occurs on a dollar-for-dollar basis. The evidence is stronger in support of the hypothesis that both Food stamps and Medicaid have substituted for AFDC than that Food stamps alone has done so, for some tests reject the food-stamps-only model. Additional results suggest that the Food stamp pracam has also slowed the adoption of the AFDCU program.

There are several implications of the findings of the paper. First, the basic result that the transfer package has increased over time in line with the growth of income suggests that the benefit will continue to grow in the future, at least to the extent that income growth also maintains its past pattern. Thus there is no reason in these results to expect any decline in redistribution. 
Second, the results imply that lump-sum transfer programs enacted by Congress have no effect on the total transfer, and therefore on the net incomes, of low-income female heads. Instead, they merely displace cash transfers with in-kind transfers. As a matter of perhaps naive political speculation, one may wonder why congress has enacted such a program; the answer may be that there are stronger political lobbies (agriculture, hospitals) behind in-kind transfers than behind cash transfers. Be that as it may, the implication is that congress simply does not have the ability to increase transfers, at least not in tris fashion. Instead, it can on ly provide a large measure of budget relief to the states. There are, of course, other policies available to Congress should it truly wish to increase the level of transfers. As discussed in the paper, heavier use of matching rates would provide nontrivial price incentives, at least on average. Alternatively, federalization of the AFDC progran would directly eliminate the ability of states to counter federal transfer policy, or the establishment of a minimum benefit would constrain that ability. Optimal federal policy under these conditions should be a topic for future research. 
APPENDIX A

LIKELIHOOD FUNCTION FOR THE RLC MODEL

The PLC model for 1960 is the Eallowing:

$$
\begin{aligned}
& B_{i}^{*}=\alpha+\beta \hat{P}_{j i}+\gamma \hat{Y}_{j i}+\varepsilon_{i} \\
& B_{i}=B_{i}^{*}+v_{i}
\end{aligned}
$$

where $B_{i}$ is the observed benefit, $B_{i}^{*}$ is the "desired" (i.e., utilitymaximizing) benefit, $\hat{P}_{j i}$ is the virtual price on segment $j, \hat{Y}_{j i}$ is virtual income on segment $j, \varepsilon_{i}$ is heterogeneity error, and $v_{i}$ is "random" error. The error terms $\varepsilon_{i}$ and $v_{i}$ are assumed to be normal $1 y$ and independently distributed with respective variances $\sigma_{\varepsilon}^{2}$ and $\sigma_{v}^{2}$. Virtual price and income are equal to:

$$
\begin{aligned}
& \hat{\mathrm{E}}_{1 i}=(.17)\left(\mathrm{C}_{i} / \mathrm{N}_{i}\right) \\
& \hat{\mathrm{P}}_{2 i}=\left(1-\mathrm{s}_{i}\right)\left(\mathrm{C}_{i} / \mathrm{N}_{i}\right) \\
& \hat{\mathrm{P}}_{3 i}=\left(\mathrm{C}_{i} / \mathrm{N}_{i}\right) \\
& \hat{\mathrm{Y}}_{1 i}=\mathrm{Y}_{i}
\end{aligned}
$$




$$
\begin{aligned}
& \hat{Y}_{2 i}=\hat{Y}_{1 i}+\left(\hat{P}_{2 i}-\hat{P}_{1 i}\right) \hat{B}_{1 i} \\
& \hat{Y}_{3 i}=\hat{Y}_{2 i}+\left(\hat{P}_{1 i}-\hat{P}_{2 i}\right) \hat{B}_{2 i}
\end{aligned}
$$

where $C_{i}$ and $N_{i}$ are the state caseload and population, respectively; and $\hat{B}_{1 i}$ and $\hat{B}_{2 i}$ are the two kink points in the constraint.. The log likelihood function to be maximized w.r.t. the parameters $\alpha, \beta, \gamma, \sigma_{E}$, and $\sigma_{v}$ is:

$$
L=\sum_{i} \log g\left(B_{i}\right)
$$

where $g$ is the density function for $B_{i}$. When 1984 is included in the estimation, an extra term for a linear regression equation is added to (A9). The density function $g$ is defined as the following:

$$
\begin{aligned}
& g\left(B_{i}\right)=\operatorname{Prob}\left(\varepsilon_{i}<\hat{B}_{1 i}-\alpha-\beta \hat{P}_{1 i}-\gamma \hat{Y}_{1 i}, \varepsilon_{i}+\nu_{i}=B_{i}-\alpha-\beta \hat{P}_{1 i}-\gamma \hat{Y}_{1 i}\right) \\
& +\operatorname{Prob}\left(\hat{B}_{1 i}-\alpha-\beta \hat{P}_{1 i}-\gamma \hat{Y}_{1 i}<\varepsilon_{i}<\hat{B}_{1 i}-\alpha-\beta \hat{P}_{2 i}-\gamma \hat{Y}_{2 i} v_{i}=B_{i}-\hat{B}_{1 i}\right) \\
& +\operatorname{Prob}\left(\hat{B}_{1 i}-\alpha-\beta \hat{P}_{2 i}-\gamma \hat{Y}_{2 i}<E_{i} \hat{B}_{2 i}-\alpha-\beta \hat{P}_{2 i}-\gamma \hat{Y}_{2 i}\right. \\
& \varepsilon_{i}+v_{i}=B_{i}-\alpha-\beta \tilde{P}_{2 i}-\hat{Y Y}_{2 i}
\end{aligned}
$$




$$
\begin{aligned}
& +\operatorname{Prob}\left(\hat{B}_{2 i}-\alpha-\hat{B} \hat{P}_{2 i}-\gamma \hat{Y}_{2 i}<\varepsilon_{i}<\hat{B}_{2 i}-\alpha-\beta \hat{P}_{3 i}-\gamma \hat{Y}_{3 i},\right. \\
& \left.v_{i}=B_{i}-\hat{B}_{2 i}\right) \\
& +\operatorname{Prob}\left(\varepsilon_{i}>\hat{B}_{2 i}-\alpha-\hat{\beta P} \hat{P}_{3 i}-\gamma \hat{Y}_{3 i}, \varepsilon_{i}+\nu_{i}=B_{i}-\alpha-\beta \hat{P}_{3 i}-\gamma \hat{Y}_{3 i}\right) \\
& =\frac{1}{\sigma_{w}} f\left(z_{1 i}\right) F\left(r_{1 i}\right)+\frac{1}{\sigma_{y}} f\left(u_{1 i}\right)\left(F\left(e_{12 i}\right)-F\left(e_{11 i}\right)\right) \\
& +\frac{1}{\sigma_{\omega}} f\left(z_{2 i}\right)\left[F\left(r_{2 b i}\right)-F\left(r_{2 a i}\right)\right]+\frac{1}{\sigma_{\nu}} f\left(u_{2 i}\right)\left[F\left(e_{23 i}\right)-F\left(e_{22 i}\right)\right] \\
& +\frac{1}{\sigma_{\omega}} \mathrm{f}\left(z_{3 i}\right)\left[1-F\left(r_{3 i}\right)\right]
\end{aligned}
$$

where $f$ and $F$ are the unit normal density and distribution functions, respectively, and

$$
\begin{aligned}
& z_{1 i}=\left(B_{i}-\alpha-\beta \hat{P}_{1 i}-\gamma \hat{Y}_{1 i}\right) / \sigma_{\omega} \\
& z_{2 i}=\left(B_{i}-\alpha-\beta \hat{P}_{2 i}-\gamma \hat{Y}_{2 i}\right) / \sigma_{\omega} \\
& z_{3 i}=\left(B_{i}-\alpha-\beta \hat{P}_{3 i}-\gamma \hat{Y}_{3 i}\right) / \sigma_{\omega} \\
& u_{1 i}=\left(B_{i}-\hat{B}_{1 i}\right) / \sigma_{v} \\
& u_{2 i}=\left(B_{i}-\hat{B}_{2 i}\right) / \sigma_{v}
\end{aligned}
$$




$$
\begin{aligned}
& e_{11 i}=\left(\hat{B}_{1 i}-\alpha-\beta \hat{P}_{1 I}-\gamma \hat{Y}_{1 i}\right) / \sigma_{\varepsilon} \\
& e_{12 i}=\left(\hat{B}_{1 i}-\alpha-\beta \hat{P}_{2 i}-\hat{Y} \hat{Y}_{2 i}\right) / \sigma_{E} \\
& e_{22 i}=\left(\hat{B}_{2 i}-\alpha-\beta \hat{P}_{2 i}-\gamma \hat{Y}_{2 i}\right) / \sigma_{E} \\
& e_{23 i}=\left(\hat{B}_{2 i}-\alpha-\beta \hat{P}_{3 i}-Y \hat{Y}_{3 i}\right) / \sigma \varepsilon \\
& r_{1 i}=\left(e_{11 i}-\rho z_{1 i}\right) / v /-\rho^{2} \\
& r_{2 a i}=\left(e_{12 i}-\rho z_{2 i}\right) / \sqrt{ }-\rho^{2} \\
& r_{2 b i}=\left(e_{22 i}-p z_{2 i}\right) / \sqrt{ } 1-p^{2} \\
& r_{3 i}=\left(e_{23 i}-\rho z_{3 i}\right) / \sqrt{ } 1-\rho^{2} \\
& \sigma_{\omega}=\left(\sigma_{\varepsilon}^{2}+\sigma_{\nu}^{2}\right)^{1 / 2} \\
& \rho=\sigma_{\varepsilon} / \sigma_{\omega}
\end{aligned}
$$


APPENDIX B

DATA SOURCES

B: Real AFDC Guarantee for a Family of Four. 1960: J.S. House Committee on ways and Means, Backgrourd Material and Data on programs withir the Jurisdiction of the Committee on Ways and Means, 1987 Edition, PQ. 660662. 1984: Unpublished data, Office of Family Assistance, Department of Health and Human Services. Nominal guarantees deflated by the personai consumption expenditure deflator (PCE) for the GNP accounts.

F: Real Food Stamp Guarantee for a Family of Four. 1984: 0.S. House Committee on Ways and Means, Background Material..., p. 504. Deflated by the PCE.

M: Real Medicaid Insurance Value. 1984: Calculated by multiplying the average Medicaid expenditure for an AFDC family of four by the ratio of AFDC families having Medicaid expenditures to all AFDC families. The average Medicaid expenditure for an AFDC family of four is calculated by suming the average Medicaid expenditure per AFDC adult and the average Medicaid expenditure per AFDC dependent times three. Medicaid expenditures obtained from unpublished data of the Health Care Financing Administration; AFDC data source described below. Deflated by $Q$ (see below).

C: AFDC Caseload. 1960: Number of families and number of recipients from Social Security Administration, Social Security Bulletin, November 1960 , P. 55. 1984: Office of Research and Statistics, quarteriy Public Assistance Statistics, July-September 1984, Table 1. 
N: Population. 1960, 1984: Bureau of Economic Analysis, state personal Income: $1929-1932$.

s: Matching Rate. 1960: unpublished data provided by L. Orr. $1984:$ Social Security Administration, Annual Statistical Supplement of the social Security Bulletin, 1983

$Y$ : Real Disposable Income per Capita. $1960 ; 1984:$ Real per capita income obtained from BEA, State personal Income .... 1960: Federal taxes obtained from Bureau of the Census, Statistical Abstract of the U.S. 1964 Edition. 1984: Federal taxes obtained from Internal Revenue Service, SOI Bulletin, Fall 1986. Taxes divided by population. Deflated by PCE.

$\mathrm{P}_{\mathrm{N}}:$ Price of Non-AFDC Medicaid Benefit. Caseload of non-AFDC Medicaid recipients obtained from unpublished HCFA data; population as referenced above; matching rate as referenced above.

Q: price of Medical Care. State-specific medical care index for 1980 obtained from T. Grannemann and M. Pauly (1983, pp. 109-110). Converted to 1984 value using the medical care component of the CPI. 
Appendix Table $\mathrm{C}-1$

Means of other Variables

Used in Main Analysis

\begin{tabular}{lcc}
\hline NE & 1960 & 1984 \\
\hline NC & .19 & .19 \\
W & .25 & .25 \\
PCHS & .23 & .23 \\
METPCT & 41.40 & 66.91 \\
UN & .61 & .61 \\
RW & 5.41 & 323.06 \\
\hline
\end{tabular}


Appendix Table $c-2$

Means of Variables in the

AFDCU Analysis

\begin{tabular}{|c|c|c|}
\hline & 1968 & 1984 \\
\hline D & .44 & .48 \\
\hline$P_{1}^{a}$ & 8.58 & 17.6 \\
\hline $\begin{array}{l}\text { Real Manufacturing } \\
\text { Wage }\end{array}$ & 303.03 & 323.06 \\
\hline $\begin{array}{l}\text { Male Unemployment } \\
\text { Rate }\end{array}$ & 3.91 & 6.46 \\
\hline$x^{b}$ & 7.28 & 10.19 \\
\hline Northeast & .19 & .19 \\
\hline
\end{tabular}

Notes:

$n=48$

aultiplied by 1000 .

boivided by 1000 


\section{NOTES}

1. An additional question is whether the changes in the caseload are explainable by the changes in the benefit. Although an interesting question, it will not be examined here. However, some research has inaicated that cross-section AFDC participation equations do not provide sufficiently large benefit elasticities to explain more than a small fraction of the tripling of the caseload. Put differently, there seens to have been a structural change in the AFDC participation equation over the period $1966-1972$.

2. The AFDC benefit per family shown in Figure 1 peaked earlier because there was a steady decline in the mean AFDC family size over the period. The guarantee is the appropriate variable to examine.

3. These considerations suggest quite naturaliy that a state may Iump aII income-maintenance-related expenditures into a single pot which constitutes a single argument in the utility function. The state may thus be concerned in setting oniy the share of its budget going toward income maintenance in general.

4. The Food Stamp benefit is also affected by the AFDC benefit itself, but orr used an instrumental variables technique to remove this source of endogeneity.

5. It appears that only time-series variation was utilized because Gramlich regressed the AFDC benefit for a weighted sum of AFDC and the Food Stamp benefit) on the Food stamp benefit and a set of state dumies, using a 
cross-section of states from 1974 to 1981 . The inclusion of state dummies sweeps out any cross-sectional variation in Food stamps, leaving only time-series variation.

6. It is assumed that federal taxes are exogenous to the median state voter, being set instead by the median U.S. voter.

7. Equation (12) assumes that AFDC and Medicaid benefits are matched at the same rate, as will be the case for the years used in the analysis.

8. The matching rate is the same in both portions.

9. One could also test nulis on the substitutability of non-AFDC Medicaid expenditures and AFDC Medicaid expenditures, but this is not directly germane to the question of interest here. In addition, of course, perfect substitutability does not correspond to a value of 1 for the utility parameter $\delta$.

10. Although it would be desirable to improve the efficiency of the estimates by pooling a set of years either before or after the transition period; this is not practical. The AFDC guarantee is next available in 1964 , then in 1968 , both years uncomfortably close to the explosive transformations of the 1960 ; and the years in the 1980 s earlier than 1984 are less assurediy post-adjustment years.

11. Alaska and Hawai are excluded because some of the variables are not present for then in 1960 . Arizona is also excluded because it has no Medicaid program.

12. The caseload variable is lagged three years to avoid potential endogeneity. However, from past work (Moffitt, 1984) it appears that there is little difference in the estimates when the current caseload is used. 
13. The benefit schedule in 1984 was linear, for the states were then employing the open-ended Medicaid matching schedule instead of the nonlinear, convex "federal" matching schedule. The Medicaid schedule created a nonconvex kink in the overall budget set. Another reason for avoiding the late 1960 s and 1970 s for estimation is that those years were a period of gradual switching from one schedule to the other, and states of ten did not switch immediately when it was advantageous for them to do so. See orr (1976, 1978) and Moffitt (1984) for discussions.

14. Forecasts for the estimates in columns (2) and (3) of that table were also calculated. Their point estimates were very close to those for column (1) but their standard errors of forecast were much higher, no doubt because of the larger number of insignificant coefficients in those regressions.

15. Since $M$ is included in virtual income, there is some endogeneity in the variable. However, the Food stamp and Medicaid terms in the virtual income variable are miniscule in magnitude, constituting less than onetenth of one percent of income. Consequently, the coeficients of the equations are virtually identical when they are left out of virtual income.

16. To test for random effects, a sample estimate of the variance of a permanent state effect was calculated for Model III. The estimated variance was less than zero (negative variances are possible in such ANOVA calculations), from which it was concluded that the data from the two years could be safely pooled and the equations estimated with oLs. 
17. This calculation uses the coefficients in Model III in Table 5 , but the mean benefits, matching rates, and so on for 1960 and 1984 separately.

18. The price elasticity in the equation is -.13 as compared to the -.08 elasticity in Moffitt $(1984)$. This is responsible for part of the difference between the results in the earlier study and those here, but not the major part.

19. Partly for this reason, only the AFDCU choice equation will be estimated below and not the benefit equations. But in addition, there are too few observations to estimate separate benefit equations on AFDCU and nonAFDCU states.

20. Allowing the transfer to husband-wife Eamilies to constitute a separate argument in the utility function--e.g*, $U(B, B, Z)$--makes the derivation of demand functions for $B$ and properties of $D^{*}$ intractable, the difficulty arising because the first two arguments are constrained to equality.

21. Given the evidence of weak state-specific effects obtained in the last section, no error components models were estimated. 
REFERENCES

Gramlich, E., "An Econometric Examination of the New Federalism," Brookings Papers on Economic Activity, 2 (1982): 327-370.

Grannemann, T. and M. PaulY, Controlling Medicaid Costs. Washington:

Anerican Enterprise Institute, 1983.

Hausman, 3., "The Econometrics of Nonlinear Budget Sets," Econometrica, 53

(Novernber 1985): $1255-1282$.

Hulten, C.; J. MCCallum; E. Durman; and R. Michel, "A Model of state

Determination of AEDC Benefits," Washington, D.C.: The Urban Institute, 1982.

Megdal, S., "The Flypaper Effect Revisited: An Econometric Explanation,"

Review of Economics and Statistics, 69 (May 1987), 347-351.

Moffitt, R., "The Effects of Grants-in-Aid on state and Local Expenditures,"

Journal of Public Economics, 23 (1984): 279-305.

"The Econometrics of Piecewise-tinear Budget Constraints: A

Survey and Exposition of the Maximum Likelihood Method," Journal of

Business and Economic Statistics, 4 (July 1986): 317-328.

Orr, L., "Income Transfers as a public Good: An Application to AFDC,"

American Economic Review, 66 (June 1976): 359-371.

, "Income Transfers as a Public Good: Reply," American Economic

Review, 58 (December 1978): 990-994.

- "Food Stamps for AFDC Families: Income Supplementation or Fiscal

Relief," Mimeographed, U.S. Department of Health and Human Services, 1979 . 
Plotnick, R., "An Interest Group Model of Direct Income Redistribution," Review of Economics and Statistics, 68 (November 1986): 594-602.

Plotnick, R. and R. Winters, "A Politico-Economic Theory of Income Redistribution," American Political Science Review, 79 (June 1985): 458473. 